\title{
Os efeitos da cultura
psicanalítica na
relação terapêutica
}

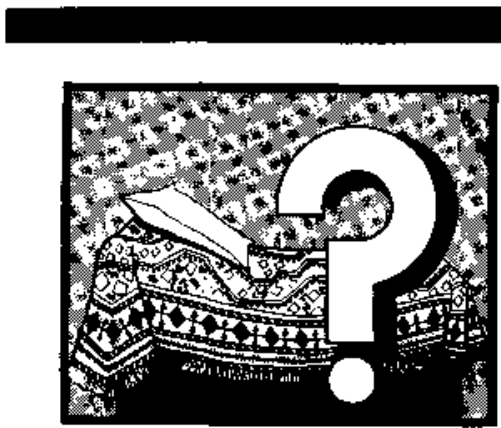

Sérvulo Augusto Figueira é psicólogo, professor no Curso de Psicologia da PUC-RJ, vice-presidente da Sociedade Brasileira de Psicanálise do Rio de Janeiro, autor de Contexto Social da Psicanálise (Francisco Alves, 1981)e organizador de coletâneas como Cultura da Psicanálise (Brasiliense, 1985). Seus estudos sobre a cultura psicanalítica vêm apontando novas problematizaçōes para a teoria e a prática psicoterápicas. Mais ainda, servem de referencial básico para se analisar o contexto das "culturas locais", nos quais se inserem as psicoterapias, enfatizando, sobretudo, que as psicoterapias e os contextos culturais estäo imbricados de formas indissociáveis.

Quando se trata de estudar as relaçōes entre psicoterapia e cultura, surgem questōes que os psicanalistas näo costumam considerar como pensáveis psicanaliticamente e ficam fora das definições oficiais da Psicanálise. Entre essas várias questöes deixadas fora do campo psicanalítico, existem duas que são muito importantes: a) o papel da difusão sobre o desenvolvimento da própria psicanálise nos planos teórico, técnico e institucional; b) o papel das culturas nacionais no desevolvimento das várias "psicanálises nacionais."

A dificuldade com essas duas questões é que não estão apenas epis- temologicamente fora do campo científico da Psicanálise mas, na verdade, as pessoas que pensam essas questōes são vistas como sendo não-psicanalistas, pelos psicanalistas mais comuns, pela maioria dominante. Essas questões quando são pensadas acabam sendo vistas com um certo cheiro de heterodoxia e de assunto perigoso e estranho. Os psicanalistas, em geral, reagem acionando processos de exclusão simbólica ou adotam essa forma de excomunhão perpétua, assumi$\mathrm{da}$ quando definem que o sujeito que se interessa por essas questões não é psicanalista ou isso não é Psicanálise.

Inicialmente, a Psicanálise surge com Freud em Viena, dentro de um padrão de cultura alemã, e tão logo começa a se organizar também começa a se difundir, por ene meios. Os primeiros são as publicações, os comentários de boca-em-boca, as fofocas nos cafés de Viena. Muito cedo começa a entrar no circuito de popularizaçào e a atingił outras pessoas que não sejam Freud. Depois, a Psicanálise começa a se difundir de Viena para outros países e culturas regionais. Esse processo todo de transplante envolve uma série de adaptaçōes e várias delas aparecem, num primeiro momento, como distorções. $\mathrm{O}$ caso norte-americano é o mais conhecido, porque se fala muito que eles distorceram a Psicanálise. Na verdade, não há uma distorção propriamente dita, porque a situação original da Psicanálise em Viena não é uma régua firme que depois seria distorcida por outras culturas; essa distorção ocorre somente em termos relativos. Assim, toda a vez que a Psicanálise entra num País, ela sofre uma série de distorçōes entre aspas, por conta das tradiçōes intelectuais locais e também por conta dos primeiros intérpretes que, quase invariavelmente, impōem um certo grau de distorção daquela situação vienense original.

No Brasil, a Picanálise tem uma história e, a partir basicarnente da década de 70 , ela começa a se difundir maciçamente por várias vias e se estabelece o que poderíamos chamar de uma cultura psicanalítica. Esse termo evidentemente é um exagero porque é uma metáfora e uma hipérbole combinadas, mas serve para descrever o que acontece com a psicanálise quando ela atinge um tal grau de popularização que passa a funcionar como uma "visão de mundo". Num artigo publicado na coletânea $C$ ultura da Psicanálise (Brasiliense, 1985), defino a cultura psicanalítica em termos de ethos (ou código de emoçōes), de eidos (um outro código para organização do pensamento) e dialeto psicologizante. No entanto, o que nos importa é que encontramos fragmentos de psicanálise, expressões ligadas a ela, valores, éticas, modelos e sub-modelos, enfim uma grande manifestação fragmentária da Psicanálise em vários casos da vida cultural. Quais efeitos isso pode ter sobre a Psicanálise propriamente dita?

O primeiro efeito mais óbvio observa-se nas formas de recrutamento de pacientes em geral ou de recrutamento de "candidatos" a psicanalistas. Num lugar em que a Psicanálise se torna tão popular, também passa a ser incensada, idealizada, $e$ isso tem o efeito de aumentar a demanda de formação psicanalística e, portanto, envolve razōes financeiras, de narcisismo, de oportunismo etc., como também aumenta a demanda de pacientes para se submeterem à análise ou às terapias em geral.

Além desse primeiro efeito mais óbvio, existern outros muito mais sutis. Por exemplo, numa cultura psicanalítica, a experiência de ser psicoanalisado ou psicoterapeutizado tem o papel de iniciação e de acesso ao bem simbólico específico que é a Psicanálise. Nesse sentido, existe uma manipulação dela pelos grupos sociais em termos de criar limites entre os que 
estão dentro e os que estão fora do círculo dos "efeitos" psicanalíticos. Várias pessoas vão procurar análise literalmente apenas para pertencer a essa cultura. É uma situação meio absurda, mas acontece.

Essa constatação cria uma condição interessantíssima porque a Psicanálise, em maior ou menor grau, faz sempre o seu trabalho em cima de um movimento subversivo muito localizado que é confundido por muita gente como se ela fosse uma grande subversäo da ordem social estabelecida - o que ela não é. Fez-se essa confusão na França durante a década de 60, na Argentina também, com o fato de a Psicanálise ser intrinsecamente subversiva. Sempre enfrento esse argumento do seguinte modo: a psicanálise sempre e inescapavelmente leva a alguma forma de adaptação social. A prova disso é que nunca, ninguém, jamais publicou um artigo psicanalítico dizendo que o paciente se suicidou e que esta conclusão do tratamento foi ótima. Esse é o exemplo máximo ou a prova paradoxal de que a Psicanálise leva sempre a alguma forma de adaptação, pois o suicídio, como a quebra mais radical com a ordem social, não é aceitável. Em termos sociológicos, a Psicanálise é basicamente uma subversão daquilo que foi introjetado pelo sujeito como norma, ordem e valor da sociedade em que vive. Qualquer que seja a Psicanálise (Freud, Klein, Lacan etc.), ela envolve sempre, na sua prática, um afrouxamento e relativização dos valores introjetados e um questionamento desses valores ou dessas formas canônicas dentro do sujeito. Nesse sentido, é uma subversāo localizada através do processo de descoberta do sujeito sobre seu próprio desejo, da emergência do conflito, do Édipo etc. Ela sempre aponta e está baseada cm uma ideologia individualista de descobrir o seu próprio caminho, através do processo de individualização, o qual sempre passa por uma discriminação entre um caminho mais individualizado e as formas herdadas de determinação cultural, familiar, desejo de pai, de mãe, do que o sujeito deveria ser etc. Então, há sempre um trabalho de distinção do sujeito em relação à cultura na qual ele está localizado em termos das identidades e do projeto que formou para si próprio. E assim que funciona a experiência analítica numa cultura comum.

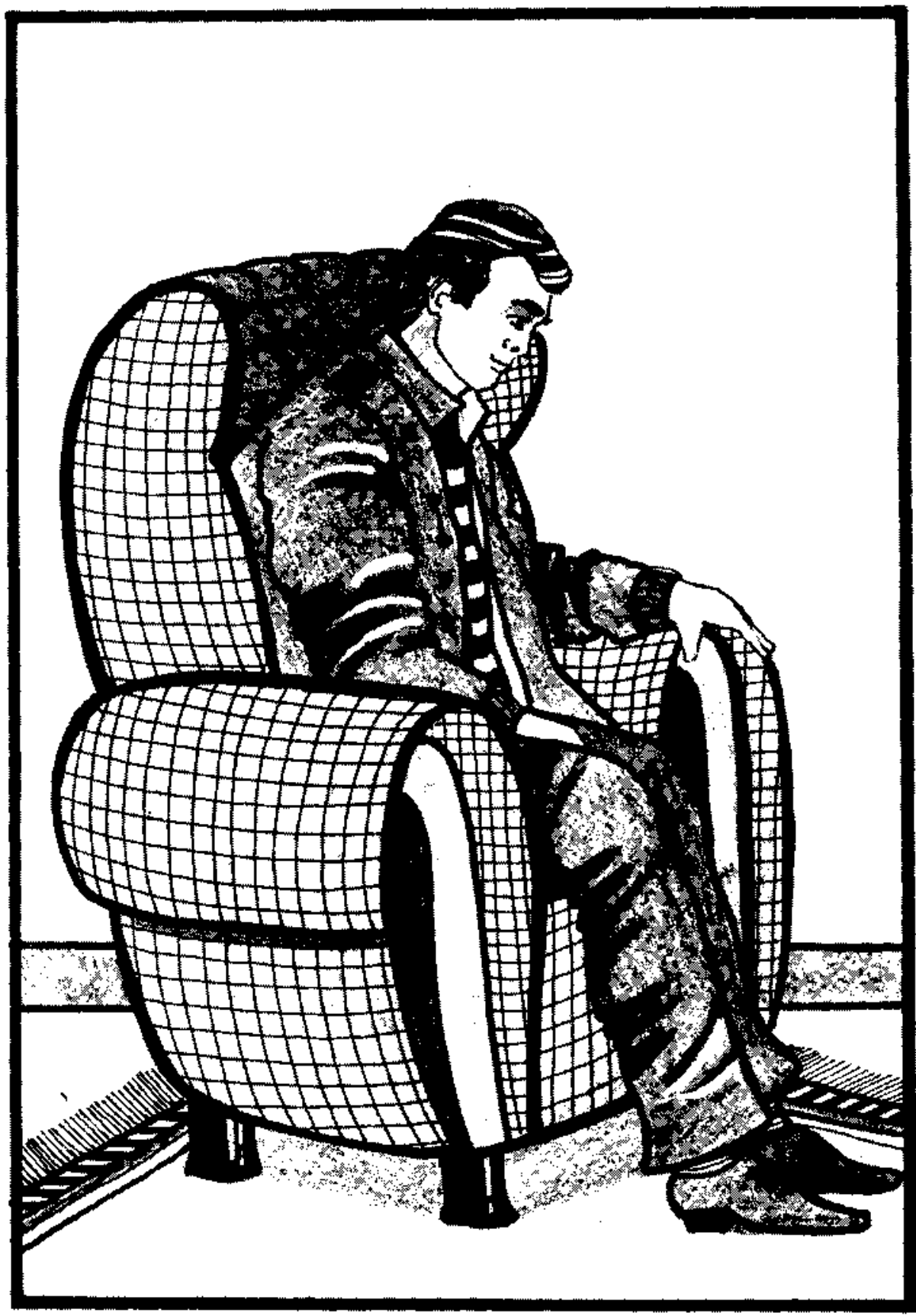

Agora, se a cultura for uma cultura psicanalítica, fica muito interessante porque se coloca o ser analisado, se torna compulsório, em termos de uma via de acesso aos grupos, à linguagem, aos códigos, aos patamares dominantes dessa cultura. Ó paciente vem fazer análise e já vem programado para sofrer um afastamento $\mathrm{em}$ relação à sua cultura dominante, só que essa cultura dominante passa por esse aspecto da relação do sujeito com a cultura psicanalítica. A cultura coloca a análise como um aliado e como um passaporte necessário para acesso a ela, senão o sujeito é excluído dela e não tem acesso aos bens simbólicos. Como a experiência psicanalítica pressuporia uma relativização desses bens culturais que cercam o sujeito, $o$ esforço de relativização fica bloqueado pelo fato de que a Psicanálise é demanda da cultura. Isso cria um efeito muito curioso porque diminui, de fora para dentro, toda a possibilidade de individuação através do processo terapêutico. Não é que o impeça, mas diminui esse impacto e 
cria um problema extra para o psicanalista, em países como o Brasil.

No Brasil, um dos problemas para o psicanalista trabalhar é a própria relação que o paciente tem com a Psicanálise: o que quer dela, o que espera dela etc. Entender isso é um recurso técnico para tentar lidar com essa situação que é uma redundância entre o que a Psicanálise vai fazer e o que a cultura exige. A cultura psicanalítica tende a esvaziar o processo psicanalítico e tende a controlá-lo de diferentes modos. Não somente se espera que a pessoa faça análise, como também espera-se que questione, ou seja, esse questionamento é esperado, exigido e concedido. E uma situação inteiramente diferente de uma cultura que se vê ameaçada pelo discurso psicanalítico, como foi a cultura de classe média da década de 50 , no Rio de Janeiro. Hoje, a cultura de, por exemplo, Ipanema de pessoas com 25,30 anos, a cultura não é ameaçada pelo exercício da Psicanálise; ao contrário, ela é reforçada e controla a Psicanálise.

Além disso, a experiência psicanalítica é controlada de outros modos bern mais concretos. Por exemplo, uma pessoa está em análise há dois meses e vive uma experiência emocionalmente perturbadora como analisando. Entrou com insônia e agora além disso está com gastrite, depressão e vontade de se matar. Esse paciente perplexo e angustiado vai falar com um amigo e este responde: "Olha, é assim mesmo, é assim que análise funciona. Eu também passei por isso. Fulano passou por muito pior do que você. Isso é uma fase: você piora agora, depois melhora".

Bem, estas duas pessoas pertencem a uma espécie de Sociedade de Amigos da Psicanálise. Através desta, há um processo de socialização da experiência psicanalítica, tornando possível obter um conhecimento sobre como a experiência acontece e, de certa forma, há um controle de fora para dentro dos passos dessa experiência. Portanto, novamente, ocorre um esvaziamento do impacto emocional e subversivo da experiência psicanalítica sobre o paciente.

Un outro modo de controle é o conhecimento sobre psicanálise caracterizado como o de um consumidor expert. Numa cultura como a brasileira, a Psicanálise se tornou um produto para a classe média como, por exemplo, queijo ou vinho branco se tornaram nos últimos anos. Há dez anos atrás, ninguém na classe média sabia o que era vinho branco. De repente, começou a ser produzido aqui e se desenvolvan todo um conhecimento sobre produção, tipo de uva, safra etc. A mesma coisa aconteceu com a Psicanálise.

Já vivi situaçōes em que havia de oito a dez pessoas numa mesa de jantar e eu era o único psicanalista presente. A conversa entre elas era assim: "Fulano está em análise com o doutor $x$ is. Pois é, todo paciente do xis fica assim! Que coisa incrivel! E o doutor ipsilon? Bem, este já tem um outro estilo". Então, não se faz sómente um comentário sobre Psicanálise enquanto generalidade, mas há um comentário específico sobre o que as pessoas consideram ser o efeito daquele produto altamente individualizado. Assim, os pacientes chegam para fazer análise já controlados multiplamente, o que tem todo um efeito de esvaziamento da novidade da experiência psicanalítica - a qual deveria ser uma possibilidade de transcender o conhecido. Entretanto, há neste caso um efeito de controlar o desconhecido ao máximo, não é que se controle real e premeditadamente, mas certamente tem-se a ilusão de um saber.

Até agora, falei dos vários efeitos da psicanálise difundida desde a perspectiva do paciente. Agora, poderia falar da perspectiva do psicanalista. A difusão pode causar um efeito de grande confusionamento no analista. Por exemplo, a Psicanálise tem um enorme preconceito contra o uso da cabeça por parte do paciente. Isso quer dizer o seguinte: quer ver o analista nervoso? $\mathrm{E}$ quando um paciente começa a falar de idéias muito sofisticadas. Em uma dona-de-casa, que não trabalha fora, isso tem um papel de racionalização muito grande. É muito diferente, no entanto, se essas idéias vêm de um professor livre. docente de Sociologia da UNICAMP, que fala de Marx e Weber porque isso faz parte da cultura profissional dele, isso nāo pode ser tratado pelo analista do mesmo modo como uma racionalização ou intelectualização.

Agora imaginem a confusāo que ocorre quando, além do uso do intelecto, os pacientes começam a poder utilizar o conhecimento psicanalítico e informaçōes sobre o processo psica- nalítico. Conheço muitos pacientes que dominam muito mais teoria psicanalítica do que o analista deles. Às vezes, eles sabem coisas incriveis a respeito do analista: sua técnica, sua formação, seu passado etc. É como se os analisandos estivessem tendo acesso aos bastidores da Psicanálise. Criase uma série de dificuldades para o analista.

Há dificuldades grandes em como lidar com esse paciente que demanda intervenção analítica. Se ele está numa cultura psicanalítica em que é normativo fazer análise, ele deseja a interpretação. E claro que estou caricaturizando um pouco, mas em algum grau isso se encontra em várias situações, de vários pacientes. Se o paciente demanda a interpretaçāo, todo efeito perturbador que a interpretação vai ter pode ser neutralizado pelo fato de o sujeito desejar a perturbação. A perturbação não perturba mais na medida em que é desejada. $O$ que exige que $O$ analista aprenda a lidar ou desenvolva meios de lidar com todos esses efeitos de redundância ou eco, que existe entre ele e o paciente, criados pela cultura psicanalítica.

Existe um fenômeno muito curioso: em 1901, quando Freud escreveu Sobre os sonhos, ele descobriu algo que quase ninguém comenta hoje. Quando o paciente entra em análise e é virgem em análise, os sonhos dele são muito mais transparentes. Assim que o paciente percebe como o analista trata o sonho, qual é o procedimento interpretativo da Psicanálise, as defesas usam esse conhecimento adquirido no contato com o analista para complexificarem os sonhos. Isso indica que há no psiquismo lugares que aprendem esses códigos vindos do analista. $O$ que faz isso no trabalho onírico deve ser certamente a função de elaboração secundária que diagrama, organiza e faz a edição do sonho. É claro que esse efeito de micro-difusão psicanalítica é um efeito estruturante para a produção de sintomas, para produção de sonhos $e$, por assim dizer, na própria produção do fato mental. Estou indo mais longe e radicalizando tal visão: a cultura psicanalítica nāo exerce somente um controle externo c circunstancial, mas cla entra de certa forma na trama do psiquismo, tendo assim um impacto grande sobre a prática psicanalítica em países como o Brasil. 